\title{
EVALUASI KESIAPAN IMPLEMENTASI ISO 31000:2009 PADA DEPARTEMEN TEKNIK INDUSTRI UNIVERSITAS DIPONEGORO
}

\author{
Naniek Utami Handayani, Diana Puspita Sari, Dhindi Oxiana Irawan, Zihramna Afdi \\ Departemen Teknik Industri, Fakultas Teknik, Universitas Diponegoro, \\ Jl. Prof. Soedarto, SH, Kampus Undip Tembalang, Semarang, Indonesia 50275
}

(Received: January 30, 2017 / Accepted: February 28, 2017)

\begin{abstract}
Abstrak
Departemen Teknik Industri sebagai bagian dari Fakultas Teknik Universitas Diponegoro dituntut untuk terus meningkatkan kualitas dan daya saingnya agar mampu melaksanakan tugas Tri Dharma Perguruan Tinggi dan menghasilkan lulusan yang dapat diterima pada lapangan kerja. Sebagai institusi pendidikan Departemen Teknik Industri tidak terlepas dari berbagai tantangan dan risiko terhadap kegagalan manajemen kegiatan terkait Tri Dharma Perguruan Tinggi. Risiko-risiko tersebut dapat menyebabkan kerugian yang jika tidak diantisipasi dapat menurunkan daya saing dan kredibilitas institusi. Tingkat kerugian akibat risiko yang dihadapi sangat bervariasi bergantung penyebab dan dampaknya terhadap institusi. Pada institusi pendidikan, risiko yang dihadapi tidak sekedar berupa finansial tetapi juga ketidakefektifan proses belajar mengajar, kegagalan mahasiswa dalam memperoleh kelulusan, dan rendahnya peluang lulusan untuk mendapatkan pekerjaan. Penelitian ini bertujuan untuk mengevaluasi kesiapan implementasi Manajemen Risiko ISO 31000:2009 pada Departemen Teknik Industri. Tujuan implementasi manajemen risiko adalah menjaga agar aktivitas operasional yang dilakukan tidak menimbulkan kerugian yang melebihi kemampuan entitas untuk menyerap kerugian tersebut ataupun membahayakan kelangsungan proses pencapaian visi. Penelitian ini berfokus pada peningkatan kualitas sumber daya manusia, peningkatan kualitas proses belajar mengajar dan peningkatan kualitas output lulusan. Penelitian dilakukan dengan metode wawancara dan observasi langsung. Berdasarkan hasil wawancara didapatkan 45 risiko yang mungkin terjadi pada Departemen Teknik Industri. Risikorisiko tersebut didapat dari 6 konteks atau sasaran yang terkait dengan tujuan yang ingin dicapai oleh Departemen Teknik Industri. Hasil dari pengolahan data menunjukkan terdapat 2 risiko dengan tingkat extremely high, 9 risiko dengan tingkat high, 27 risiko dengan tingkat medium, dan 7 risiko dengan tingkat low. Mitigasi risiko dilakukan untuk risiko dengan tingkat extremely high dan high.
\end{abstract}

Kata kunci: implementasi manajemen risiko; ISO 31000:2009; mitigasi risiko

\begin{abstract}
Department of Industrial Engineering as part of the Faculty of Engineering, University of Diponegoro required to continuously improve the quality and competitiveness to be able to carry out the taskof Tri Dharma Universities and produce graduates who can be accepted in the field of employment. As an educational institution of the Department of Industrial Engineering is inseparable from the various challenges and risks to management failures related activities Tri Dharma Universities. The risks that can cause harm if not anticipated can lower the competitiveness and credibility of institutions. The level of loss due to the risk of facing the highly variable dependent causes and its impact on the institution. In educational institutions, the risks faced not only be financial but also the ineffectiveness of teaching and learning, student failure in obtaining the graduation, and the low chances of graduates to get jobs. This study aimed to evaluate the readiness of the implementation of ISO 31000 : 2009 Risk Management in the Department of Industrial Engineering. The purpose of implementation of risk management is to keep operational activities that do not result in losses that exceed the entity's ability to absorb such losses or endanger the continuation of the process of achieving the vision. This research focuses on improving the quality of human resources, improving the quality of teaching and learning processes and improving the quality of graduate output. Research conducted by interview and direct observation.
\end{abstract}

\footnotetext{
${ }^{*}$ Penulis Korespondensi.

email: naniekh@ft.undip.ac.id
} 


\begin{abstract}
Based on the results of interviews obtained 45 risks that may occur in the Department of Industrial Engineering. These risks come from 6 context or goal related to the objectives to be achieved by the Department of Industrial Engineering. The results of processing the data shows that there are two risks with extremely high levels, 9 risk with high levels, 27 medium risk level, and 7 risks with low leve ls. Risk mitigation is done to extremely high level risk and high level risk.
\end{abstract}

Keywords : implementation of risk management; ISO 31000 : 2009, risk mitigation

\section{Pendahuluan}

Perguruan Tinggi sebagai institusi pendidikan menjalankan misi kemanusian yang sangat penting yaitu mencerdaskan kehidupan bangsa dalam berbagai aspek pengembangan keilmuan dan juga etika, norma, dan moral anak bangsa. Departemen Teknik Industri sebagai bagian dari Fakultas Teknik Universitas Diponegoro harus mampu meningkatkan kualitasnya agar mampu menghasilkan lulusan yang mampu bersaing pada tingkat regional maupun internasional. Sebagai institusi pendidikan, Departemen Teknik Industri terus berupaya untuk memberikan yang terbaik dalam proses pembelajaran dengan mengacu pada visi, misi, dan tujuan yang telah ditetapkan.

Proses belajar mengajar sebagai kegiatan inti pada Departemen Teknik Industri didukung oleh berbagai proses yaitu administrasi, penelitian dan pengembangan, dan keorganisasian lainnya. Dalam pelaksanaan di lapangan terdapat beberapa kendala yang dihadapi seperti ketidakpastian dan risiko. Risiko secara umum didefinisikan sebagai potensi terjadinya suatu peristiwa baik yang diperkirakan maupun yang tidak dapat diperkirakan dan dapat menimbulkan dampak bagi pencapaian tujuan. Pengelolaan institusi pendidikan akan selalu menghadapi suatu tantangan risiko, karena apa yang akan terjadi di masa akan datang tidak dapat diketahui secara pasti. Besarnya tingkat kerugian sebagai dampak risiko yang dihadapi sangat bervariasi bergantung pada penyebab dan pengaruhnya terhadap output dan outcome secara keseluruhan. Pada institusi pendidikan, risiko yang dihadapi tidak sekedar risiko kerugian secara finansial tetapi juga risiko ketidakefektifan proses belajar mengajar, risiko kegagalan mahasiswa dalam memperoleh kelulusan dan pekerjaan dan lain-lain.

Pengendalian risiko merupakan permasalahan yang sering diabaikan sehingga peluang terjadinya risiko tidak dapat langsung diamati secara jelas. Oleh sebab itu, implementasi manajemen risiko diperlukan dalam pengelolaan institusi agar dapat meminimasi peluang risiko kegagalan. Manajemen risiko merupakan suatu kegiatan untuk mengenali risiko yang dihadapi oleh sebuah entitas dan bagaimana mengendalikan risiko tersebut. Tujuan utama manajemen risiko adalah menjaga agar aktivitas operasional yang dilakukan tidak menimbulkan kerugian yang melebihi kemampuan entitas untuk menghadapi kerugian tersebut ataupun membahayakan kelangsungan proses pencapaian visi. Salah satu elemen risiko yang pasti akan muncul dalam aktivitas manajemen pada suatu entitas adalah risiko operasional yang merupakan risiko tertua dan bersifat inheren yang muncul sebelum risiko yang lainnya. Dalam prosesnya, terdapat banyak metode yang dapat diterapkan untuk melaksanakan manajemen risiko.
ISO 31000:2009, Risk management - Principles and guidelines, berisi prinsip-prinsip, framework dan proses untuk mengelola risiko. Penerapan ISO 31000 dapat membantu organisasi menaikkan kemungkinan pencapaian tujuan, memperbaiki identifikasi peluang-peluang dan ancaman-ancaman. Penerapan ISO 31000 dapat membantu organisasi serta secara efektif mengalokasikan dan menggunakan sumber daya untuk menghadapi risiko. ISO 31000 tidak digunakan untuk tujuan sertifikasi, artinya tidak/belum ada sertifikat ISO 31000 untuk suatu organisasi, tetapi ISO 31000 bisa digunakan untuk program audit/assessment manajemen risiko. Organisasi yang menerapkan standard ini dapat membandingkan praktek manajemen risikonya dengan organisasi lain (bencmarking). Organisasi yang menerapkan standard ini dapat terbantu mewujudkan manajemen dan tata kelola yang efektif dan efisien.

Penelitian ini bertujuan untuk mengevaluasi kesiapan implementasi prinsip-prinsip yang tertuang dalam ISO 31000:2009 pada Departemen Teknik Industri Fakultas Teknik Universitas Diponegoro dalam konteks atau sasaran peningkatan kualitas sumber daya manusia, peningkatan kualitas proses belajar mengajar, dan peningkatan kualitas output/lulusan.

\section{Metodologi Penelitian \\ Definisi Risiko}

The International Standardd Organization (dalam ISO Guide 73:2009 Risk Management - Vocabulary) menjelaskan risiko sebagai dampak yang ditimbulkan dari ketidakpastian dalam upaya mencapai objektif. Risiko sering ditandai dengan kejadian yang berpotensi muncul dan konsekuensi yang ditimbulkan, atau kombinasi dari keduanya. Risiko juga sering digambarkan sebagai kombinasi dari konsekuensi atas suatu kejadian (termasuk perubahan dalam suatu kondisi) dan kemungkinan yang berhubungan dengan suatu kejadian.

\section{Definisi Manajemen Risiko}

Menurut AS/NZS 4360:2004, manajemen risiko adalah kultur, proses, dan struktur yang diarahkan kepada manajemen yang efektif mengenai peluang - peluang yang potensial dan pengaruh - pengaruh yang merugikan. Sedangkan, menurut (Smith, 1990) manajemen risiko merupakan proses identifikasi, pengukuran, dan kontrol keuangan dari sebuah Risiko yang mengancam aset dan penghasilan dari sebuah perusahaan atau proyek yang dapat menimbulkan kerusakan atau kerugian pada perusahaan tersebut. Manajemen risiko juga merupakan suatu aplikasi 
dari manajemen umum yang mencoba untuk mengidentifikasi, mengukur, dan menangani sebab dan akibat dari ketidakpastian pada sebuah organisasi (William dan Richard, 1963). Tujuan manajemen risiko adalah sebagai berikut:

a. Melindungi perusahaan dari risiko signifikan yang dapat menghambat pencapaian tujuan perusahaan.

b. Memberikan kerangka kerja manajemen risiko yang konsisten atas risiko yang ada pada proses bisnis dan fungsi-fungsi dalam perusahaan.

c. Mendorong menajemen untuk bertindak proaktif mengurangi risiko kerugian, menjadikan pengelolaan risiko sebagai sumber keunggulan bersaing, dan keunggulan kinerja perusahaan.

d. Mendorong setiap insan perusahaan untuk bertindak hati-hati dalam menghadapi risiko perusahaan, sebagai upaya untuk memaksimalkan nilai perusahaan.

e. Membangun kemampuan mensosialisasikan pemahaman mengenai risiko dan pentingnya pengelolaan risiko.

f. Meningkatkan kinerja perusahaan melalui penyediaan informasi tingkat risiko yang dituangkan dalam peta risiko (risk map) yang berguna bagi manajemen dalam pengembangan strategi dan perbaikan proses manajemen risiko secara terus menerus dan berkesinambungan

\section{Manajemen Risiko Berbasis ISO 31000:2009}

Manajemen risiko berbasis ISO 31000:2009 memperhatikan tiga aspek penting yang ditekankan dalam standard yaitu, pertama, penerapan manajemen risiko harus disertai komitmen yang tinggi dari pengurus organisasi (corporate boards), dalam perusahaan berarti Direksi dan Komisaris; kedua, manajemen risiko harus diintegrasikan ke dalam seluruh proses organisasi dan menjadi bagian yang tidak terpisahkan dari core responsibilities para pemilik/penanggung jawab proses (dalam perusahaan adalah para manajer dan staf di setiap departemen), dan manajemen risiko harus merupakan bagian dari proses pengambilan keputusan baik pada tingkat governance maupun manajerial. Kerangka kerja manajemen risiko berdasarkan ISO 31000:2009 disajikan pada Gambar 1.

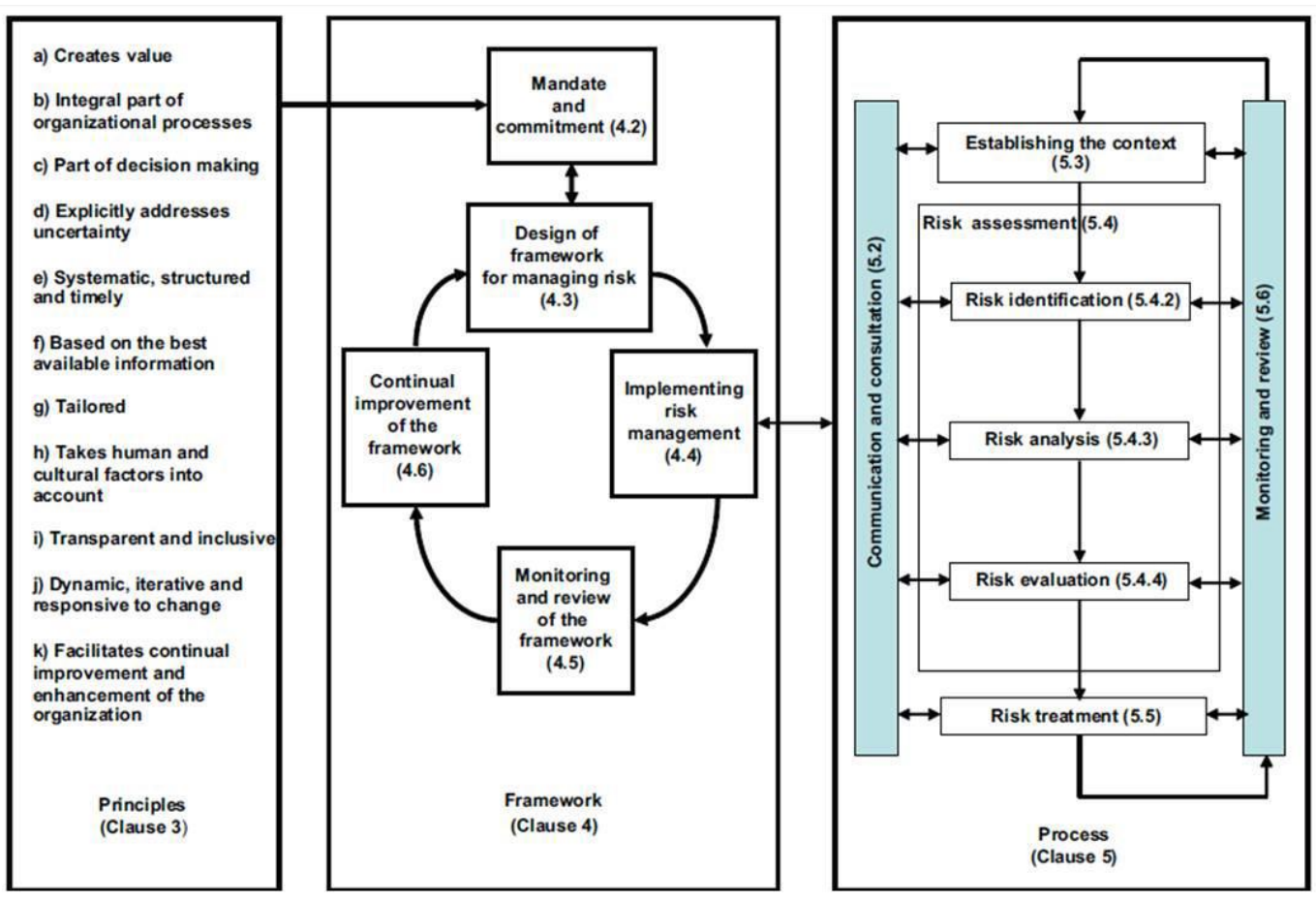

Relationships between the risk management principles, framework and process based on ISO 31000:2009

Gambar 1. Framework Manajemen Risiko ISO 31000:2009

\section{Kerangka Kerja Implementasi Manajemen Risiko Menurut ISO 31000:2009}

Proses manajemen risiko merupakan kegiatan kritikal dalam manajemen risiko, karena merupakan penerapan dari pada prinsip dan kerangka kerja yang telah dibangun. Proses manajemen risiko terdiri dari tiga proses besar, yaitu:

1. Penetapan konteks (establishing the context)

Penetapan konteks bertujuan untuk mengidentifikasi dan mengungkapkan sasaran organisasi, lingkungan dimana sasaran hendak dicapai, stakeholders yang berkepentingan, dan keberagaman kriteria risiko, dimana hal-hal ini akan membantu mengungkapkan dan menilai sifat dan kompleksitas dari risiko. Terdapat empat konteks yang perlu ditentukan dalam penetapan konteks, yaitu konteks internal, konteks eksternal, konteks manajemen risiko, dan kriteria risiko. 

2. Penilaian risiko (risk assessment)

Penilaian risiko terdiri dari:

a. Identifikasi risiko: mengidentifikasi risiko apa saja yang dapat mempengaruhi pencapaian sasaran organisasi.

b. Analisis risiko: menganalisis kemungkinan dan dampak dari risiko yang telah diidentifikasi.

c. Evaluasi risiko: membandingkan hasil analisis risiko dengan kriteria risiko untuk menentukan bagaimana penanganan risiko yang akan diterapkan.

3. Penanganan risiko (risk treatment): dalam menghadapi risiko terdapat empant penanganan yang dapat dilakukan oleh organisasi yaitu menghindari risiko (risk avoidance), mitigasi risiko (risk reduction), transfer risiko kepada pihak ketiga (risk sharing), menerima risiko (risk acceptance)

Ketiga proses besar tersebut didampingi oleh dua proses yaitu:

4. Komunikasi dan konsultasi

Komunikasi dan konsultasi merupakan hal yang penting mengingat prinsip manajemen risiko yang kesembilan menuntut manajemen risiko yang transparan dan inklusif, dimana manajemen risiko harus dilakukan oleh seluruh bagian organisasi dan memperhitungkan kepentingan dari seluruh stakeholders organisasi. Adanya komunikasi dan konsultasi diharapkan dapat menciptakan dukungan yang memadai pada kegiatan manajemen risiko dan membuat kegiatan manajemen risiko menjadi tepat sasaran.

5. Monitoring dan review

Hal ini diperlukan untuk memastikan bahwa implementasi manajemen risiko telah berjalan sesuai dengan perencanaan yang dilakukan. Hasil monitoring dan review juga dapat digunakan sebagai bahan pertimbangan untuk melakukan perbaikan terhadap proses manajemen risiko.

Manajemen risiko merupakan proses esensial dalam organisasi untuk memberikan jaminan yang wajar terhadap pencapaian tujuan organisasi. ISO 31000: 2009 Risk Management - Principles and Guidelines merupakan standard yang dibuat untuk memberikan prinsip dan panduan generik dalam penerapan manajemen risiko. Standard ini menyediakan prinsip, kerangka kerja, dan proses manajemen risiko. Prinsip manajemen risiko merupakan fondasi dari kerangka kerja dan proses manajemen risiko, sedangkan kerangka kerja manajemen risiko merupakan struktur pembangun proses manajemen risiko. Proses manajemen risiko merupakan penerapan inti dari manajemen risiko, sehingga harus dijalankan secara komprehensif, konsisten, dan terus diperbaiki sesuai dengan keperluan. Implementasi manajemen risiko berbasis ISO 31000: 2009 secara mendetail dan menyeluruh pada ketiga komponen tersebut diharapkan dapat meningkatkan efektivitas manajemen risiko organisasi.

\section{Hasil dan Pembahasan \\ Penetapan Visi, Misi, dan Tujuan Departemen \\ Teknik Industri}

Visi Departemen Teknik Industri adalah:
Menjadi Departemen Teknik Industri yang unggul di bidang riset keteknik-industrian di tingkat regional untuk menghasilkan lulusan yang “COMPLETES” pada tahun 2020. adalah:

Adapun misi Misi Departemen Teknik Industri

1. Menyelenggarakan pendidikan yang terbaik (excellent) dalam bidang Teknik Industri, sehingga menghasilkan lulusan yang "COMPLETES" dan memiliki keunggulan kompetitif;

2. Melakukan kegiatan riset, publikasi, dan kerjasama di bidang standardisasi, logistik, ebussines, dan human factor dengan pihak industri serta upaya kepemilikan HAKI sebagai pengembangan Departemen Teknik Industri;

3. Melaksanakan pengabdian kepada masyarakat untuk menghasilkan solusi tepat guna terhadap permasalahan riil di UKM dan Pemerintah sebagai upaya penerapan keilmuan Teknik Industri;

4. Mengembangkan jejaring kerja sama dengan para stakeholder guna mendukung penciptaan jiwa entrepreneurship lulusan;

5. Melakukan improvement dan evaluasi secara teratur dan terus-menerus untuk meningkatkan akuntabilitas, komitmen mutu, profesionalisme, dan tata kelola serta kemandirian dalam rangka mewujudkan sustainability penyelenggaraan Departemen Teknik Industri. adalah:

Sedangkan Tujuan Departemen Teknik Industri

1. Meningkatkan kompetensi sumber daya manusia dalam bidang Teknik Industri yang berdaya guna dan berdaya saing di tingkat nasional maupun regional;

2. Menghasilkan lulusan yang unggul di bidang keteknik-industrian yang memiliki dasar pengetahuan, ketrampilan, dan sikap profesional serta dilandasi jiwa entrepreneurship sehingga mampu menghadapi tantangan karir di era global dalam bidang perancangan, perbaikan, implementasi dan pengelolaan sistem terpadu pada industri manufaktur dan jasa;

3. Meningkatkan kualitas dan kuantitas riset serta pengabdian masyarakat yang dilaksanakan oleh civitas Departemen Teknik Industri untuk memecahkan permasalahan yang ada di masyarakat khususnya yang berhubungan dengan keteknik-industrian dan melakukan publikasi baik tingkat nasional maupun internasional;

4. Menjalin kerja sama dengan pihak industri, masyarakat, dan institusi lain dalam lingkup nasional maupun internasional;

5. Meningkatkan efektivitas tata kelola pelayanan akademik dan keuangan;

6. Mendapatkan akreditasi internasional dari lembaga akreditasi yang kredibel. 


\section{Penetapan Konteks Manajemen Risiko pada Departemen Teknik Industri}

Sasaran dari Departemen Teknik Industri yang ditetapkan yaitu sebagai berikut:

1. Peningkatan kualitas sumber daya manusia di Departemen Teknik Industri dengan pendidikan lanjut, pelatihan dan sertifikasi (terkait tujuan 1)

2. Peningkatan kualitas proses pembelajaran dan penyediaan program dan layanan akademik yang relevan dengan kebutuhan (terkait tujuan 2)

3. Peningkatan kualitas output lulusan dengan pengetahuan dan keterampilan yang tinggi di bidang teknik industri, kemampuan berkomunikasi yang baik, berkarakter dan memiliki jiwa wirausaha (terkait tujuan 2)

4. Peningkatan kualitas riset, publikasi, dan pengabdian masyarakat (terkait tujuan 3)

5. Peningkatan kerjasama dengan institusi dalam dan luar negeri (terkait tujuan 4)

6. Penyelenggaraan sistem keuangan dan sistem pengelolaan yang transparan, terdokumentasi dengan baik dan dapat dipertanggungjawabkan (terkait tujuan 5 dan 6)

\section{Identifikasi Risiko}

Identifikasi risiko dilakukan berdasarkan keenam konteks yang telah dijelaskan sebelumnya. Berikut merupakan risiko-risiko yang mungkin terjadi:

1. Peningkatan kualitas sumber daya manusia di Departemen Teknik Industri dengan pendidikan lanjut, pelatihan dan sertifikasi (terkait tujuan 1)

R.1 Kurangnya jumlah dosen S3

R.2 Kurangnya jumlah profesor

R.3 Bidang keahlian dosen belum sepenuhnya menunjang kompetensi lulusan

R.4 Tidak terpenuhinya pelatihan pengajaran untuk dosen yang diperlukan

R.5 Tidak terpenuhinya sertifikasi untuk dosen yang diperlukan

R.6 Kenaikan pangkat yang rumit

2. Peningkatan kualitas proses pembelajaran dan penyediaan program dan layanan akademik yang relevan dengan kebutuhan (terkait tujuan 2)

R.7 Perencanaan kurikulum yang tidak relevan dengan kebutuhan pasar

R.8 Buruknya perencanaan RPS dan kontrak kuliah

R.9 Pelaksanaan PMB (Proses Belajar Mengajar) yang tidak sesuai

R.10 IP dan IPK mahasiswa yang rendah

R.11 Adanya mahasiswa yang tidak lulus matakuliah

R.12 Masa studi mahasiswa panjang

R.13 Adanya mahasiswa DO (drop out)

R.14 Ruang kuliah tidak cukup

R.15 Fasilitas media pembelajaran tidak cukup

R.16 Fasilitas laboratotium yang tidak cukup

R.17 Fasilitas internet yang kurang memadai

R.18 Pelayanan akademik kurang responsif

3. Peningkatan kualitas output lulusan dengan pengetahuan dan keterampilan yang tinggi di bidang teknik industri, kemampuan berkomunikasi yang baik, berkarakter dan memiliki jiwa wirausaha (terkait tujuan 2)

R.19 Kurangnya kesempatan lomba bagi mahasiswa

R.20 Kurangnya kesempatan publikasi bagi mahasiswa

R.21 Kurangnya pembekalan lulusan

R.22 Tidak adanya kerjasama dengan badan sertifikasi profesi

R.23 Lulusan tidak terserap di lapangan kerja

R.24 Kemampuan softskill lulusan kurang

R.25 Ketidakpuasan pengguna

4. Peningkatan kualitas riset, publikasi, dan pengabdian masyarakat (terkait tujuan 3)

R.26 Penurunan minat penelitian dosen

R.27 Penurunan minat penelitian mahasiswa

R.28 Penurunan jumlah publikasi (seminar) nasional dosen

R.29 Penurunan jumlah publikasi (jurnal) nasional dosen

R.30 Penurunan jumlah publikasi nasional mahasiswa

R.31 Penurunan jumlah publikasi (seminar) internasional dosen

R.32 Penurunan jumlah publikasi (jurnal) internasional dosen

R.33 Penurunan jumlah publikasi internasional mahasiswa

R.34 Penurunan minat dosen dalam pengabdian masyarakat

R.35 Penurunan minat mahasiswa dalam pengabdian masyarakat di Program Kreativitas Mahasiswa (PKM)

R.36 Penurunan minat mahasiswa dalam pengabdian masyarakat di Program Mahasiswa Wirausaha (PMW)

5. Peningkatan kerjasama dengan institusi dalam dan luar negeri (terkait tujuan 4)

R.37 Tidak ada link and match antara kebutuhan industri dengan kurikulum

R.38 Kurangnya kerjasama double degree diluar negeri

R.39 Kurangnya kerjasama dalam magang yang disediakan

6. Penyelenggaraan sistem keuangan dan sistem pengelolaan yang transparan, terdokumentasi dengan baik dan dapat dipertanggungjawabkan (terkait tujuan 5)

R.40 Alokasi anggaran tidak mendukung program kerja

R.41 Penyusunan RBA tidak sesuai dengan IKU/IKK

R.42 Alokasi anggaran tidak berdasarkan jumlah penerimaan (UKT)

R.43 Serapan anggaran tidak maksimal

R.44 Sulitnya belanja modal

R.45 Kebutuhan dana membengkak

\section{Analisis Risiko}

Analisis risiko dilakukan untuk mengukur skala dampak kerugian yang akan timbul jika risiko terjadi dan skala kejadian dari risiko. Skala dampak dan skala kejadian risiko disajikan pada Tabel 1 dan Tabel 2, sedangkan tingkatan risiko dan matriks risiko yang 
digunakan untuk mengetahui risiko yang harus terlebih dahulu dilakukan mitigasi risiki disajikan pada Tabel 3 dan Tabel 4.

\section{Evaluasi Risiko}

Terdapat empat penanganan yang dapat dilakukan oleh organisasi: (i) Menghindari risiko (risk avoidance); (ii) Mitigasi risiko (risk reduction), dapat dilakukan dengan mengurangi kemungkinan atau dampak; (iii) Transfer risiko kepada pihak ketiga (risk sharing); (iv) Menerima risiko (risk acceptance).

\section{Pengolahan Data}

Penilaian risiko dilakukan dengan memberikan nilai dampak risiko. Tingkat keparahan dan tingkat kejadian diwakili dengan skala 1 sampai 5 disajikan pada Tabel 5.

Tabel 1. Skala Dampak Risiko

\begin{tabular}{lcl}
\hline \multicolumn{1}{c}{ Impact } & Nilai & \multicolumn{1}{c}{ Keterangan } \\
\hline $\begin{array}{l}\text { Some loss but not material; existing controls and procedures should cope } \\
\text { with event or circumstances }\end{array}$ & 1 & $\begin{array}{l}\text { Tidak berarti } \\
\text { Berpengaruh pada } \\
\text { avent with consequences that can be readily absorbed but requires } \\
\text { management effort to minimize the impact }\end{array}$ \\
$\begin{array}{l}\text { Significant event or circumstance that can be managed under normal } \\
\text { circumstances }\end{array}$ & 2 & $\begin{array}{l}\text { internal } \\
\text { Berpengaruh pada } \\
\text { area mayor atau } \\
\text { eksternal } \\
\text { Berpengaruh pada } \\
\text { Critical event or circumstance that can be endured with proper }\end{array}$ \\
$\begin{array}{l}\text { management } \\
\text { Event or circumstance with potentially disastrous impact on business or } \\
\text { significant material adverse impact on a key area }\end{array}$ & 4 & $\begin{array}{l}\text { Berpengaruh pada } \\
\text { reputasi \& asset } \\
\text { utama }\end{array}$ \\
\hline
\end{tabular}

Tabel 2. Skala Kejadian Risiko

\begin{tabular}{lcl}
\hline \multicolumn{1}{c}{ Likelihood/ Probability } & Nilai & \multicolumn{1}{c}{ Deskripsi } \\
\hline Almost certain (frequent) & 1 & Sangat jarang terjadi \\
Likely (probable) & 2 & Mungkin dapat terjadi \\
Possible (occasional) & 3 & Kadang-kadang dapat terjadi \\
Unlikely (uncommon) & 4 & Sering terjadi \\
Rare (remote) & 5 & Selalu terjadi \\
\hline
\end{tabular}

Tabel 3. Tingkat Risiko

\begin{tabular}{ccl|}
\hline Tingkat Risiko & Kode & \multicolumn{1}{c|}{ Keterangan } \\
\hline $17-25$ & E & Extreme High Risk - Risiko Sangat Tinggi \\
$10-16$ & H & High Risk - Risiko Tinggi \\
$5-9$ & M & Medium Risk - Risiko Sedang \\
$1-4$ & L & Low Risk - Risiko Rendah \\
\hline
\end{tabular}

Tabel 4. Matriks Risiko

\begin{tabular}{llllll}
\hline & 1 & 2 & 3 & 4 & 5 \\
\hline 5 & M & M & H & E & E \\
4 & L & M & H & H & E \\
3 & L & M & M & H & H \\
2 & L & L & M & M & H \\
1 & L & L & L & L & M \\
\hline
\end{tabular}


Tabel 5. Penilaian Skala Dampak dan Skala Kejadian

\begin{tabular}{|c|c|c|c|}
\hline Kode & Risk Agent & $\begin{array}{l}\text { Severity } \\
(1-5)\end{array}$ & $\begin{array}{c}\text { Probability } \\
\text { (1-5) }\end{array}$ \\
\hline R1 & Kurangnya jumlah dosen S3 & 4 & 3 \\
\hline R2 & Kurangnya jumlah profesor & 4 & 2 \\
\hline R3 & Bidang keahlian dosen belum sepenuhnya menunjang kompetensi lulusan & 4 & 1,5 \\
\hline $\mathrm{R} 4$ & Tidak terpenuhinya pelatihan pengajaran untuk dosen yang diperlukan & 3 & 2,5 \\
\hline R5 & Tidak terpenuhinya sertifikasi untuk dosen yang diperlukan & 4 & 1 \\
\hline R6 & Kenaikan pangkat yang rumit & 3,5 & 3,5 \\
\hline R7 & Perencanaan kurikulum yang tidak relevan dengan kebutuhan pasar & 5 & 1,5 \\
\hline $\mathrm{R} 8$ & Buruknya perencanaan RPS dan kontrak kuliah & 4 & 2 \\
\hline $\mathrm{R} 9$ & Pelaksanaan PMB (Proses Belajar Mengajar) yang tidak sesuai & 4 & 2 \\
\hline R10 & IP dan IPK mahasiswa yang rendah & 4 & 1,5 \\
\hline R11 & Adanya mahasiswa yang tidak lulus matakuliah & 3 & 2,5 \\
\hline R12 & Masa studi mahasiswa panjang & 4 & 1 \\
\hline R13 & Adanya mahasiswa DO (drop out) & 4,5 & 1 \\
\hline R14 & Ruang kuliah tidak cukup & 4 & 2 \\
\hline R15 & Fasilitas media pembelajaran tidak cukup & 4 & 3 \\
\hline R16 & Fasilitas laboratotium yang tidak cukup & 4 & 2 \\
\hline R17 & Fasilitas internet yang kurang memadai & 4,5 & 4 \\
\hline R18 & Pelayanan akademik kurang responsif & 3,5 & 3,5 \\
\hline R19 & Kurangnya kesempatan lomba bagi mahasiswa & 3 & 2,5 \\
\hline $\mathrm{R} 20$ & Kurangnya kesempatan publikasi bagi mahasiswa & 3 & 2,5 \\
\hline $\mathrm{R} 21$ & Kurangnya pembekalan lulusan & 3 & 2 \\
\hline $\mathrm{R} 22$ & Tidak adanya kerjasama dengan badan sertifikasi profesi & 3 & 1,5 \\
\hline $\mathrm{R} 23$ & Lulusan tidak terserap di lapangan kerja & 4 & 1 \\
\hline $\mathrm{R} 24$ & Kemampuan softskill lulusan kurang & 3,5 & 2,5 \\
\hline $\mathrm{R} 25$ & Ketidakpuasan pengguna & 4 & 1,5 \\
\hline R26 & Penurunan minat penelitian dosen & 4 & 1 \\
\hline $\mathrm{R} 27$ & Penurunan minat penelitian mahasiswa & 3,5 & 2,5 \\
\hline $\mathrm{R} 28$ & Penurunan jumlah publikasi (seminar) nasional dosen & 4 & 1 \\
\hline R29 & Penurunan jumlah publikasi (jurnal) nasional dosen & 4 & 2 \\
\hline R30 & Penurunan jumlah publikasi nasional mahasiswa & 3,5 & 2,5 \\
\hline $\mathrm{R} 31$ & Penurunan jumlah publikasi (seminar) internasional dosen & 4 & 1 \\
\hline R32 & Penurunan jumlah publikasi (jurnal) internasional dosen & 4 & 2 \\
\hline $\mathrm{R} 33$ & Penurunan jumlah publikasi internasional mahasiswa & 3,5 & 2 \\
\hline R34 & Penurunan minat dosen dalam pengabdian masyarakat & 3,5 & 1,5 \\
\hline R35 & $\begin{array}{l}\text { Penurunan minat mahasiswa dalam pengabdian masyarakat di Program } \\
\text { Kreativitas Mahasiswa (PKM) }\end{array}$ & 3 & 2,5 \\
\hline R36 & $\begin{array}{l}\text { Penurunan minat mahasiswa dalam pengabdian masyarakat di Program } \\
\text { Mahasiswa Wirausaha (PMW) }\end{array}$ & 3 & 2,5 \\
\hline R37 & Tidak ada link and match antara kebutuhan industri dengan kurikulum & 4,5 & 1 \\
\hline R38 & Kurangnya kerjasama double degree diluar negeri & 3,5 & 3 \\
\hline R39 & Kurangnya kerjasama magang yang disediakan & 3,5 & 2,5 \\
\hline $\mathrm{R} 40$ & Alokasi anggaran tidak mendukung program kerja & 5 & 3,5 \\
\hline R41 & Penyusunan RBA tidak sesuai dengan IKU/IKK & 4 & 2 \\
\hline $\mathrm{R} 42$ & Alokasi anggaran tidak berdasarkan jumlah penerimaan (UKT) & 4,5 & 3 \\
\hline $\mathrm{R} 43$ & Serapan anggaran tidak maksimal & 4,5 & 2,5 \\
\hline R44 & Sulitnya belanja modal & 4 & 3 \\
\hline R45 & Kebutuhan dana membengkak & 3,5 & 3,5 \\
\hline
\end{tabular}


Kemudian dilakukan perhitungan tingkat risiko dengan mengalikan nilai skala dampak dan skala kejadian, lalu dengan menggunakan Tabel 3 dapat dikelompokkan tingkat risiko yang termasuk dalam risiko low, medium, high, dan extreme high. Hasil penilaian tingkat risiko dilakukan oleh Ketua dan Sekertaris Departemen Teknik Industri Fakultas Teknik Universitas Diponegoro. Perhitungan tingkat risiko dan kelompok tingkat risiko dari ke-45 risiko yang ada disajikan pada Tabel 6.

Tabel 6. Perhitungan Tingkat Risiko

\begin{tabular}{|c|c|c|c|c|}
\hline \multirow{2}{*}{ Kode } & $\begin{array}{c}\text { Sever } \\
\text { ity }\end{array}$ & $\begin{array}{c}\text { Probabil } \\
\text { ity }\end{array}$ & \multirow{2}{*}{$\begin{array}{l}\text { Tingkat } \\
\text { Risiko }\end{array}$} & \multirow{2}{*}{$\begin{array}{c}\mathrm{Kod} \\
\mathrm{e}\end{array}$} \\
\hline & $(1-5)$ & $(1-5)$ & & \\
\hline $\mathrm{R} 1$ & 4 & 3 & 12 & $\mathrm{H}$ \\
\hline $\mathrm{R} 2$ & 4 & 2 & 8 & $\mathrm{M}$ \\
\hline R3 & 4 & 1,5 & 6 & $\mathrm{M}$ \\
\hline $\mathrm{R} 4$ & 3 & 2,5 & 7,5 & $\mathrm{M}$ \\
\hline R5 & 4 & 1 & 4 & $\mathrm{~L}$ \\
\hline R6 & 3,5 & 3,5 & 12,25 & $\mathrm{H}$ \\
\hline R7 & 5 & 1,5 & 7,5 & $\mathrm{M}$ \\
\hline $\mathrm{R} 8$ & 4 & 2 & 8 & $\mathrm{M}$ \\
\hline R9 & 4 & 2 & 8 & $\mathrm{M}$ \\
\hline $\mathrm{R} 10$ & 4 & 1,5 & 6 & $\mathrm{M}$ \\
\hline R11 & 3 & 2,5 & 7,5 & $\mathrm{M}$ \\
\hline $\mathrm{R} 12$ & 4 & 1 & 4 & $\mathrm{~L}$ \\
\hline $\mathrm{R} 13$ & 4,5 & 1 & 4,5 & $\mathrm{~L}$ \\
\hline R14 & 4 & 2 & 8 & $\mathrm{M}$ \\
\hline $\mathrm{R} 15$ & 4 & 3 & 12 & $\mathrm{H}$ \\
\hline R16 & 4 & 2 & 8 & $\mathrm{M}$ \\
\hline R17 & 4,5 & 4 & 18 & $\mathrm{E}$ \\
\hline
\end{tabular}

\begin{tabular}{|c|c|c|c|c|}
\hline R18 & 3,5 & 3,5 & 12,25 & $\mathrm{H}$ \\
\hline R19 & 3 & 2,5 & 7,5 & $\mathrm{M}$ \\
\hline R20 & 3 & 2,5 & 7,5 & $\mathrm{M}$ \\
\hline R21 & 3 & 2 & 6 & M \\
\hline R22 & 3 & 1,5 & 4,5 & M \\
\hline R23 & 4 & 1 & 4 & $\mathrm{~L}$ \\
\hline R24 & 3,5 & 2,5 & 8,75 & M \\
\hline R25 & 4 & 1,5 & 6 & M \\
\hline R26 & 4 & 1 & 4 & $\mathrm{~L}$ \\
\hline R27 & 3,5 & 2,5 & 8,75 & M \\
\hline R28 & 4 & 1 & 4 & $\mathrm{~L}$ \\
\hline R29 & 4 & 2 & 8 & $\mathrm{M}$ \\
\hline R30 & 3,5 & 2,5 & 8,75 & $\mathrm{M}$ \\
\hline R31 & 4 & 1 & 4 & $\mathrm{~L}$ \\
\hline R32 & 4 & 2 & 8 & M \\
\hline R33 & 3,5 & 2 & 7 & M \\
\hline R34 & 3,5 & 1,5 & 5,25 & $\mathrm{M}$ \\
\hline R35 & 3 & 2,5 & 7,5 & M \\
\hline R36 & 3 & 2,5 & 7,5 & $\mathrm{M}$ \\
\hline R37 & 4,5 & 1 & 4,5 & $\mathrm{M}$ \\
\hline R38 & 3,5 & 3 & 10,5 & $\mathrm{H}$ \\
\hline R39 & 3,5 & 2,5 & 8,75 & M \\
\hline R40 & 5 & 3,5 & 17,5 & $\mathrm{E}$ \\
\hline R41 & 4 & 2 & 8 & $\mathrm{M}$ \\
\hline R42 & 4,5 & 3 & 13,5 & $\mathrm{H}$ \\
\hline R43 & 4,5 & 2,5 & 11,25 & $\mathrm{H}$ \\
\hline R44 & 4 & 3 & 12 & $\mathrm{H}$ \\
\hline R45 & 3,5 & 3,5 & 12,25 & $\mathrm{H}$ \\
\hline
\end{tabular}

Selanjutnya, berdasarkan hasil perhitungan tingkat risiko disusun matriks risiko yang disajikan pada Gambar 2. 


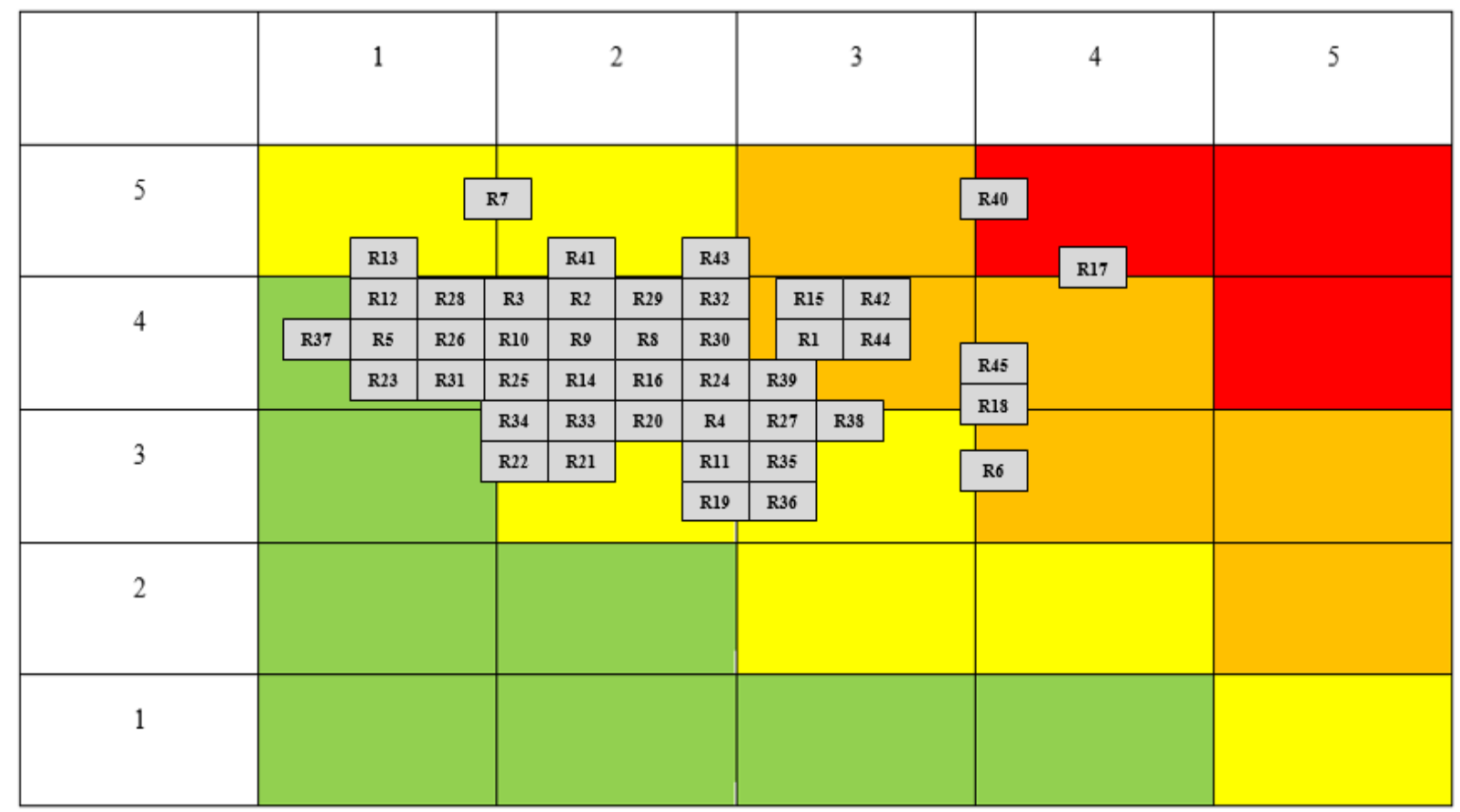

Gambar 2. Matriks Risiko

Tabel 7. Tingkat Risiko Tinggi

\begin{tabular}{lll}
\hline \multicolumn{1}{c}{ Identifikasi Risiko } & $\begin{array}{c}\text { Kode } \\
\text { Risiko }\end{array}$ & Kode Tingkat Risiko \\
\hline $\begin{array}{l}\text { Alokasi anggaran tidak mendukung } \\
\text { program kerja }\end{array}$ & R40 & E \\
\hline Kurangnya jumlah dosen S3 & R1 & H \\
\hline Kenaikan pangkat yang rumit & R6 & H \\
\hline Fasilitas media pembelajaran tidak cukup & R15 & H \\
\hline Pelayanan akademik kurang responsif & R18 & H \\
\hline $\begin{array}{l}\text { Kurangnya kerjasama double degree } \\
\text { diluar negeri }\end{array}$ & R38 & H \\
\hline $\begin{array}{l}\text { Alokasi anggaran tidak berdasarkan } \\
\text { jumlah penerimaan (UKT) }\end{array}$ & R42 & H \\
\hline Serapan anggaran tidak maksimal & R43 & H \\
\hline Sulitnya belanja modal & R44 & H \\
\hline Kebutuhan dana membengkak & R45 & H \\
\hline
\end{tabular}

Dari tabel matriks risiko diatas dapat dilihat bahwa terdapat 2 risiko pada tingkat extremely high yaitu $\mathrm{R} 17$, dan R40, terdapat 9 risiko pada tingkat high yaitu R1, R6, R15, R18, R38, R42, R43, R44, dan R45, terdapat 27 risiko pada tingkat medium yaitu R2, R3, R4, R7, R8, R9, R10, R11, R14, R16, R19, R20, R21, R22, R24, R25, R27, R29, R30, R32, R33, R34, R35, $\mathrm{R} 36, \mathrm{R} 37, \mathrm{R} 39$, dan $\mathrm{R} 41$, dan terdapat 7 risiko pada tingkat low yaitu R5, R12, R13, R23, R26, R28, R31.

Setelah melakukan penilaian tingkat risiko dilakukan langkah mitigasi untuk menangani risiko- risiko yang terjadi, dalam hal ini semua tingkat risiko diberikan usulan langkah mitigasi yang dapat dilakukan oleh Departemen Teknik Industri dalam menangani risiko yang terjadi. Mitigasi yang diusulkan hanya untuk risiko dengan tingkat extremely high dan high, dan usulan langkah mitigasi ini dilakukan dengan cara brainstorming dengan ketua dan anggota Gugus Kendali Mutu Departemen Teknik Industri Universitas Diponegoro. 
Berdasarkan Gambar 2. dapat dilihat bahwa risiko-risiko dengan tingkat extremely high dan high. Risiko-risiko tersebut disajikan pada Tabel 7.

\section{Analisis Hasil}

Manajemen risiko di Departemen Teknik Industri Fakultas Teknik Universitas Diponegoro dengan menggunakan ISO 31000:2009 dilakukan dengan menetapkan konteks yang disesuaikan dengan tujuan yang ingin dicapai Teknik Industri. Dari hasil wawancara dengan Ketua dan Sekretaris serta tim GPM Departemen Teknik Industri didapatkan enam (6) konteks yang akan dilakukan pengidentifikasian risiko, keenam konteks tersebut yaitu:

1. Peningkatan kualitas sumber daya manusia di Departemen Teknik Industri dengan pendidikan lanjut, pelatihan dan sertifikasi (terkait tujuan 1)

2. Peningkatan kualitas proses pembelajaran dan penyediaan program dan layanan akademik yang relevan dengan kebutuhan (terkait tujuan 2)

3. Peningkatan kualitas output lulusan dengan pengetahuan dan keterampilan yang tinggi di bidang teknik industri, kemampuan berkomunikasi yang baik, berkarakter dan memiliki jiwa wirausaha (terkait tujuan 2)

4. Peningkatan kualitas riset, publikasi, dan pengabdian masyarakat (terkait tujuan 3)

5. Peningkatan kerjasama dengan institusi dalam dan luar negeri (terkait tujuan 4)

6. Penyelenggaraan sistem keuangan dan sistem pengelolaan yang transparan, terdokumentasi dengan baik dan dapat dipertanggungjawabkan (terkait tujuan 5)
Hasil dari konteks yang telah ditetapkan, dibuat identifikasi risiko dari masing-masing konteks yang ada. Terdapat 45 risiko yang teridentifikasi dari keenam konteks yang ada. Kemudian dilakukan penilaian risiko dengan cara menilai dari skala dampak tingkat kerugian yang akan dialami dari masingmasing risiko dan skala kejadian seberapa sering risiko tersebut akan terjadi. Skala dampak memiliki nilai antara 1 hingga 5 , begitu pula skala kejadian juga memiliki nilai 1 hingga 5, nilai 1 merupakan tingkat yang paling rendah dan 5 merupakan nilai yang paling tinggi.

Tingkat risiko didapatkan dengan cara mengalikan skala dampak dan skala kejadian, dari 45 risiko yang teridentifikasi terdapat 2 risiko pada tingkat extremely high yaitu fasilitas internet yang kurang memadai (R17), dan alokasi anggaran yang tidak mendukung program kerja (R40), dan 9 risiko pada tingkat high yaitu kurangnya jumlah dosen S3 (R1), kenaikan pangkat yang rumit (R6), fasilitas media pembelajaran tidak cukup (R15), pelayanan akademik yang kurang responsif (R18), kurangnya kerjasama double degree diluar negeri (R38), alokasi anggaran tidak berdasarkan jumlah penerimaan (UKT) (R42), serapan anggaran tidak maksimal (R43), sulitnya belanja modal (R44), dan kebutuhan dana membengkak (R45).

Berdasarkan peringkat risiko tersebut, selanjutnya dibuat langkah mitigasi risiko yang dapat dilakukan untuk menangani risiko. Rekomendasi mitigasi risiko disajikan pada Tabel 8.

Tabel 8. Langkah Mitigasi Risiko

Identifikasi Risiko

Fasilitas internet yang kurang memadai

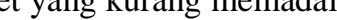

Mengusulkan penyediaan fasilitas internet (jaringan EVO) ke fakultas

Melakukan penekanan alokasi anggaran untuk setiap proker

Menaikkan porsi alokasi anggaran yang akan diusulkan ke universitas

Alokasi anggaran tidak mendukung program kerja

Mengusulkan kejelasan pembagian anggaran antara universitas, fakultas, dan departemen

Penyusunan program kerja yang mendukung IKU/IKK

Memberikan kesempatan bagi dosen S2 untuk melakukan studi lanjut

Mengusulkan bantuan tugas belajar untuk dosen ke universitas

Kurangnya jumlah dosen S3
Mengurangi sistem menunggu bagi dosen untuk melakukan studi lanjut

Mendorong dan memotivasi dosen untuk kuliah S3 terutama untuk perguruan tinggi di luar negeri 


\begin{tabular}{|c|c|}
\hline \multirow{2}{*}{ Kenaikan pangkat yang rumit } & Mempermudah mekanisme kenaikan pangkat agar lebih mudah \\
\hline & $\begin{array}{l}\text { Melakukan sosialisasi kepada dosen terkait dengan mekanisme } \\
\text { kenaikan pangkat }\end{array}$ \\
\hline \multirow[b]{2}{*}{ Fasilitas media pembelajaran tidak cukup } & Melakukan penganggaran pengadaan fasilitas ke fakultas \\
\hline & $\begin{array}{l}\text { Melakukan kerjasama dengan CSR (Corporate Social Responsibility) } \\
\text { untuk pengadaan fasilitas }\end{array}$ \\
\hline Pelayanan akademik kurang responsif & $\begin{array}{l}\text { Melakukan pelatihan untuk karyawan terkait dengan pelayanan yang } \\
\text { baik }\end{array}$ \\
\hline \multirow{2}{*}{$\begin{array}{l}\text { Kurangnya kerjasama double degree } \\
\text { diluar negeri }\end{array}$} & $\begin{array}{l}\text { Menjalin koneksi dengan perguruan tinggi diluar negeri melalui } \\
\text { dosen alumni dari perguruan tinggi tersebut }\end{array}$ \\
\hline & Melakukan inisiasi kerjasama melalui alumni perguruan tinggi asing \\
\hline $\begin{array}{l}\text { Alokasi anggaran tidak berdasarkan } \\
\text { jumlah penerimaan }(\mathrm{UKT})\end{array}$ & $\begin{array}{l}\text { Mengusulkan transparansi pembagian UKT untuk fakultas dan } \\
\text { jurusan }\end{array}$ \\
\hline \multirow{3}{*}{ Serapan anggaran tidak maksimal } & $\begin{array}{l}\text { Penyusunan RBA dengan baik dengan mempertimbangkan waktu, } \\
\text { sumber daya manusia, dan anggaran }\end{array}$ \\
\hline & Memudahkan dalam pengurusan SPJ, SK, dan lain-lain \\
\hline & Memberikan sistem informasi mengenai SPJ, SK, dan lain-lain \\
\hline Sulitnya belanja modal & Melakukan adanya alokasi anggaran khusus belanja modal \\
\hline Kebutuhan dana membengkak & $\begin{array}{l}\text { Penyusunan rencana anggaran biaya dengan baik dengan } \\
\text { memperhitungkan kenaikan mata uang }\end{array}$ \\
\hline
\end{tabular}

\section{Kesimpulan}

Berdasarkan hasil pengolahan data dan analisis yang dilakukan dapat diambil kesimpulan sebagai berikut. Hasil wawancara dengan Ketua dan Sekretaris Departemen Teknik Industri didapatkan 45 risiko yang mungkin bisa terjadi pada Teknik Industri. Risikorisiko tersebut didapat dari 6 konteks atau sasaran yang terkait dengan tujuan yang ingin dicapai oleh Teknik Industri. Sasaran pertama yaitu peningkatan kualitas sumber daya manusia di Departemen Teknik Industri dengan pendidikan lanjut, pelatihan dan sertifikasi (terkait tujuan 1) terdapat 2 risiko, sasaran kedua peningkatan kualitas proses pembelajaran dan penyediaan program dan layanan akademik yang relevan dengan kebutuhan (terkait tujuan 2) terdapat 6 risiko, sasaran ketiga peningkatan kualitas output lulusan dengan pengetahuan dan keterampilan yang tinggi di bidang teknik industri, kemampuan berkomunikasi yang baik, berkarakter dan memiliki jiwa wirausaha (terkait tujuan 2) terdapat 4 risiko, sasaran keempat peningkatan kualitas riset, publikasi, dan pengabdian masyarakat (terkait tujuan 3) terdapat 2 risiko, sasaran kelima peningkatan kerjasama dengan institusi dalam dan luar negeri (terkait tujuan 4) terdapat 2 risiko, dan sasaran keenam penyelenggaraan sistem keuangan dan sistem pengelolaan yang transparan, terdokumentasi dengan baik dan dapat dipertanggungjawabkan (terkait tujuan 5) terdapat 1 risiko.

Hasil penilaian risiko dengan menggunakan tingkat dampak dan tingkat kejadian dengan menggunakan skala 1 sampai 5, didapatkan 2 risiko pada tingkat extremely high yaitu R17, dan R40, terdapat 9 risiko pada tingkat high yaitu R1, R6, R15, R18, R38, R42, R43, R44, dan R45, terdapat 27 risiko pada tingkat medium yaitu R2, R3, R4, R7, R8, R9, R10, R11, R14, R16, R19, R20, R21, R22, R24, R25, R27, R29, R30, R32, R33, R34, R35, R36, R37, R39, dan $\mathrm{R} 41$, dan terdapat 7 risiko pada tingkat low yaitu R5, R12, R13, R23, R26, R28, R31.

Mitigasi dilakukan pada risiko dengan tingkat risiko extremely high dan high yaitu fasilitas internet yang kurang memadai (R17), dan alokasi anggaran yang tidak mendukung program kerja (R40), dan 9 risiko pada tingkat high yaitu kurangnya jumlah dosen S3 (R1), kenaikan pangkat yang rumit (R6), fasilitas media pembelajaran tidak cukup (R15), pelayanan akademik yang kurang responsif (R18), kurangnya kerjasama double degree diluar negeri (R38), alokasi anggaran tidak berdasarkan jumlah penerimaan (UKT) (R42), serapan anggaran tidak maksimal (R43), sulitnya belanja modal (R44), dan kebutuhan dana membengkak (R45). 
Mitigasi yang dapat dilakukan untuk tingkat risiko extremely high yaitu untuk fasilitas internet yang kurang memadai adalah mengusulkan penyediaan fasilitas internet (jaringan EVO) ke fakultas, dan untuk alokasi anggaran tidak mendukung program kerja adalah melakukan penekanan alokasi anggaran untuk setiap proker, menaikkan porsi alokasi anggaran yang akan diusulkan ke universitas, mengusulkan kejelasan pembagian anggaran antara universitas, fakultas, dan departemen, dan penyusunan program kerja yang mendukung IKU/IKK.

\section{Daftar Pustaka}

International Organization for Standardization (ISO). 2009. "ISO 13000:2009-Risk Management: Principles and Guidelines." Geneva.

Toma, Simona-Valeria. Alexa, Iona Veronica. Sarpe, Daniela Acunta. 2014. Identifying The Risk In Higher Education Institutions. Procedia Economics and Finance 15 ( 2014 ) 342 - 349. doi: 10.1016/S2212-5671(14)00520- 